\title{
DE PERTO E DE DENTRO: UM NOVO OLHAR SOBRE A CIDADE
}

\author{
SABER DE UM FATO NÃO É O MESMO QUE \\ VIVENCIÁ-LO. PARA ALÉM DOS PROBLEMAS, A \\ DIVERSIDADE DAS METRÓPOLES PODE OFERECER \\ EXPERIÊNCIAS INOVADORAS E DIFERENTES \\ PERSPECTIVAS SOBRE A SUA REALIDADE
}

| POR JOSÉ GUILHERME CANTOR MAGNANI

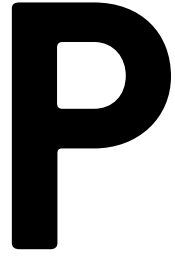

ode parecer estranho recorrer à Antropologia para tratar de temas urbanos, ainda mais no contexto das grandes cidades contemporâneas, pois, para uma visão habitual, seu objeto de estudo seriam os povos primitivos, cujos modos de vida têm como base outras formas de assentamento que não a cidade. Entretanto, mais do que uma disciplina voltada para a análise desses povos, ela é a maneira de pensar que se impõe quando o objeto é o "outro" e exige nossa própria transformação, como afirma o filósofo Merleau-Ponty.

Ademais, a Antropologia estuda fenômenos urbanos desde longa data: nos anos 1920, os etnógrafos da Escola de Chicago voltaram-se às profundas transformações pelas quais a cidade passava, e a Escola de Manchester, outra referência, analisava os problemas da destribalização no chamado copperbelt africano, nos anos 1950.

A história da Antropologia Urbana em São Paulo dialoga com essas influências, mas é principalmente na década de 1970 que se desenvolvem estudos sobre as condições de vida da população na periferia da capital paulista.

\section{DIFERENÇAS E REALIDADES DOS ESPAÇOS URBANOS}

Para avaliar a contribuição da Antropologia nesse campo, convém explorar alguns pontos sobre os rumos e consequências do processo de urbanização das cidades a partir de enfoques que, para efeitos de análise, foram agrupados em dois blocos: 


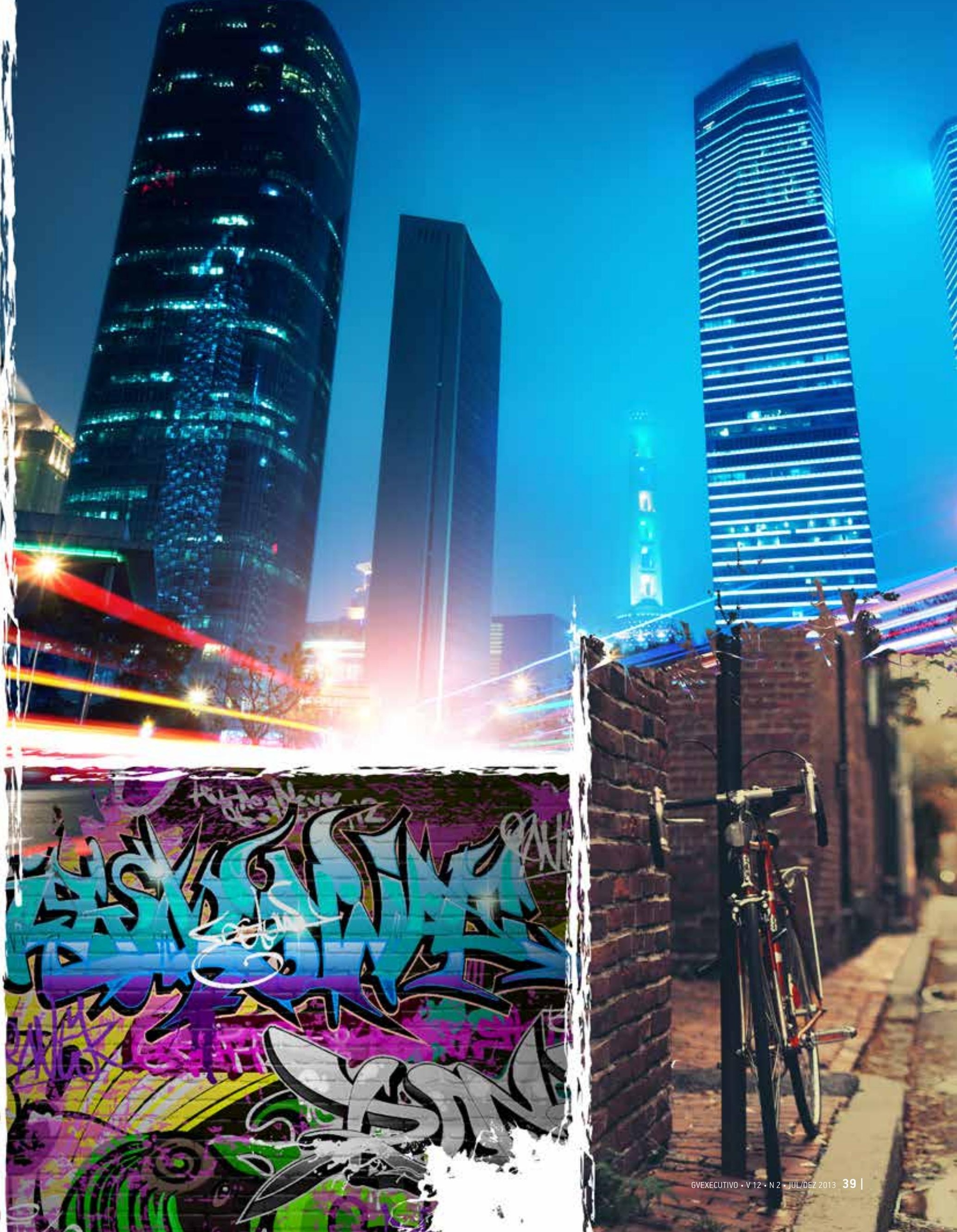


- Metrópoles dos países emergentes: notam-se aspectos desagregadores do processo de urbanização, como o colapso do sistema de transporte, as deficiências do saneamento básico, a falta de moradia, a concentração e desigual distribuição de renda, o aumento dos índices de poluição e violência. Com base em indicadores econômicos, sociológicos e demográficos, esse é o quadro geralmente aplicado a essas cidades.

- Metrópoles dos países desenvolvidos: com cenários marcados pelo consumismo, excessiva divisão e especialização, dependência da tecnologia, processos de informatização e "não-lugares". Essas são as cidades do primeiro mundo, a partir da leitura de alguns semiólogos, arquitetos e críticos pós-modernos.

No primeiro caso, fatores desordenados de crescimento acabam por produzir o caos social. No segundo, enfatiza-se a ruptura, consequência de saltos tecnológicos que tornam as formas tradicionais de comunicação e sociabilidade obsoletas, ou seja, o caos é semiológico.

Ainda que por motivos diferentes, ambas as perspectivas levam a conclusões semelhantes: desvalorização dos espaços públicos e consequente privatização da vida coletiva, limitação de contatos, confinamento em redes sociais restritas, situações de discriminação e segregação. Essa visão, apesar de reducionista, é muito recorrente no discurso da mídia e até em análises acadêmicas.

\section{PODER DO ATOR SOCIAL}

Tomando como referência o que foi dito anteriormente, o que se observa é a ausência dos atores sociais: tem-se a cidade como uma entidade à parte de seus moradores. Pensada como resultado de interesses econômicos transnacionais e de elites locais, parece um cenário desprovido de vida social, pontos de encontro e redes de troca.

Na verdade, o que mais chama a atenção é a ênfase do capital e do mercado como protagonistas. Os moradores - que em suas múltiplas formas de sociabilidade, estilos de vida, deslocamentos e divergências são quem realmente conferem vitalidade à metrópole - acabam por se tornar praticamente invisíveis. Quando o fazem, é de forma passiva, como excluídos, nas margens, nas periferias.

Mas é justamente a partir da população e de suas diversas práticas que é possível introduzir outros pontos de vista sobre a dinâmica da cidade; para além do olhar que julga o certo e o errado e dos interesses de poder, o qual decide o que é conveniente e lucrativo.

\section{PARA ALÉM DOS INTERESSES DE PODER, O QUAL DECIDE O QUE É CONVENIENTE E LUCRATIVO, A POPULAÇÃO E SUAS PRÁTICAS INTRODUZEM NOVOS PONTOS DE VISTA SOBRE A DINÂMICA DA CIDADE}

\section{AJUSTANDO O FOCO: DE PERTO E DE DENTRO}

Em um aglomerado com mais de 17 milhões de habitantes, como é o caso de São Paulo, não é possível a delimitação de um único centro. Em vez de se procurar (em vão) um princípio de ordem que garanta a dinâmica do espaço urbano como um todo, o mais correto seria identificar as diferentes centralidades e os múltiplos ordenamentos que ocorrem a partir delas.

A capital paulista não pode simplesmente ser considerada uma região que cresceu demais - daí suas mazelas e distorções. Sua escala impõe uma modificação na distribuição dos espaços públicos e no modo como interagem com o privado: haveria de se perguntar se o exercício da cidadania, das práticas urbanas e dos rituais da vida coletiva não teriam, nesse contexto, outras dimensões e modalidades.

Não há como negar os problemas, comprovados pela própria experiência do dia a dia nas metrópoles e que prejudicam a qualidade de vida da população. $\mathrm{O}$ que se propõe, porém, é uma mudança de foco. Ao invés de analisar a cidade a partir de uma perspectiva de longe e de fora, vê-la de perto e de dentro, com base nos múltiplos e heterogêneos atores sociais da vida cotidiana.

Essa mudança que a perspectiva antropológica possibilita tem a vantagem de evitar a oposição entre indivíduos e megaestruturas urbanas, presente nos discursos sobre despersonalização, massificação, confinamento etc, muito difundidos e sempre à mão quando se quer discorrer sobre os problemas dos grandes centros urbanos, sejam do primeiro ou do terceiro mundo.

É preciso considerar os espaços de convivência dos quais as pessoas participam efetivamente na dinâmica urbana. $\mathrm{O}$ simples fato de acompanhar alguns indivíduos em seus trajetos habituais revelaria um circuito formado por diferentes contatos e pontos, como o trabalho, o lazer, as práticas associativas etc.

\section{CATEGORIAS DE SOCIABILIDADE NAS CIDADES}

Alguns dos termos referidos no parágrafo anterior como trajetos e circuitos - fazem parte de uma família de categorias da Antropologia Urbana, que permitem identificar e descrever regularidades no comportamento e nas formas de uso do espaço. 


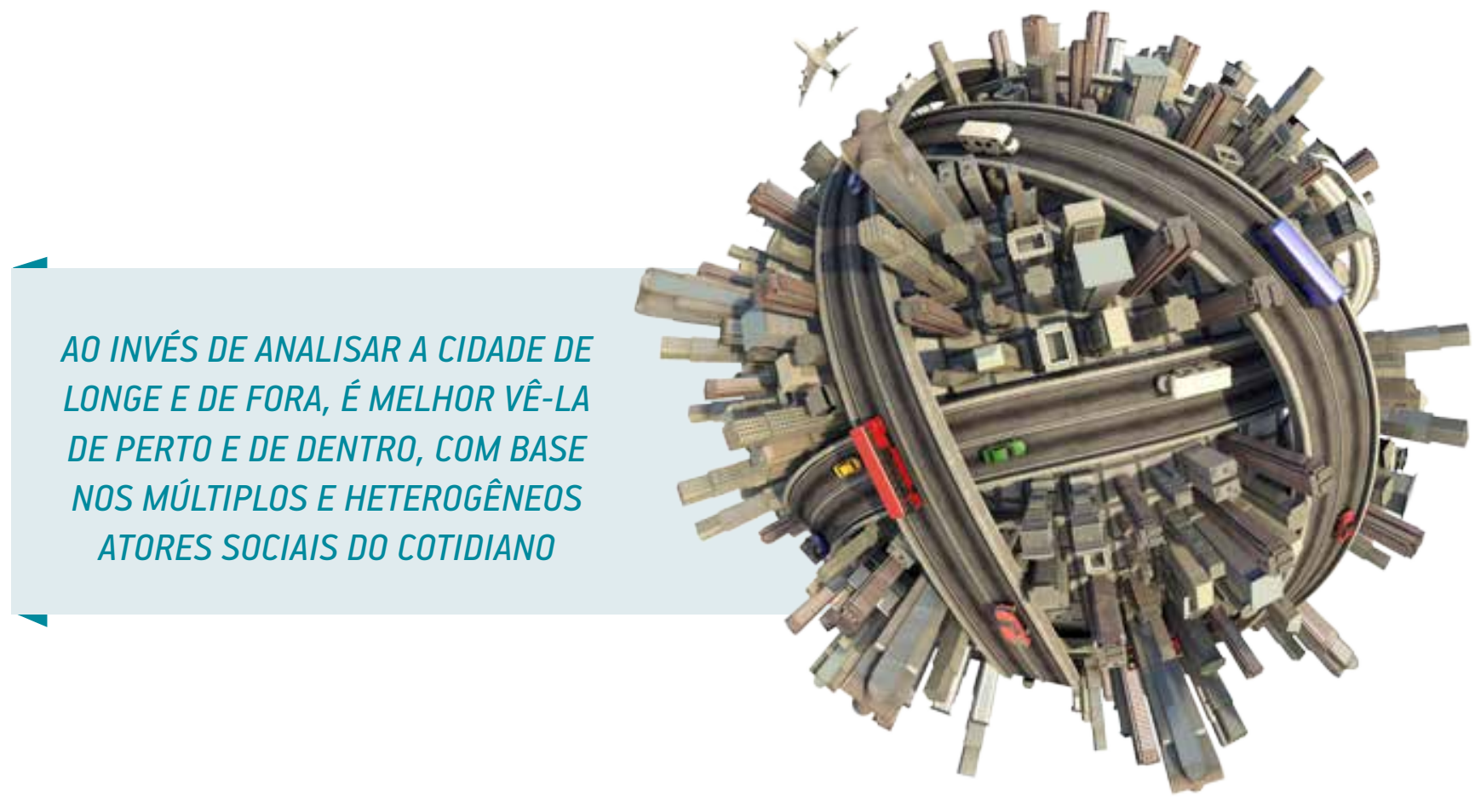

Nessas categorias inclui-se, por exemplo, o termo pedaço, que designa locais de encontro entre pessoas que compartilham os mesmos gostos, valores e códigos.

Mancha, outro termo, refere-se a espaços mais abertos e contíguos na paisagem urbana, formados por estabelecimentos que competem ou se complementam no oferecimento de determinado bem ou serviço. Um exemplo seria a mancha de lazer da Vila Madalena ou do Baixo Augusta.

Circuito é a categoria que rompe com o particularismo do pedaço e a contiguidade espacial da mancha, permitindo reconhecer e conectar pontos distantes sem perder a referência cultural que o caracteriza. Assim, o circuito gay não se restringe a esta ou aquela mancha em uma determinada região, mas congrega pontos espalhados pela cidade, bem conhecidos por seus usuários. O mesmo pode ser dito do circuito dos cinéfilos, cujos frequentadores sabem onde estão as salas cult de cinema; ou então o dos skatistas, que podem ter um de seus points na Praça Roosevelt, mas conhecem e utilizam outras pistas espalhadas pela metrópole.

Na chamada "cultura de periferia", para além da notícia em algum jornal sobre um show de rap ou um evento de hip-hop, cabe reconhecer que essas manifestações também se articulam em circuito, e não só no campo da música, mas da literatura, artes, cinema, teatro, culinária, moda etc.

Cada uma dessas modalidades, com sua linguagem própria, mobiliza temas comuns, o que constitui uma estética própria. Sua disseminação e diferenciação - que se valem da tecnologia digital para viabilizar e tornar sua produção mais acessível - fazem com que diversos desses experimentos se comuniquem e se influenciem, constituindo um circuito. Esse processo se dá principalmente nos mais de sessenta "saraus da periferia" espalhados pela cidade, ao longo dos quais transitam pessoas, ideias e textos com propostas originais; alguns de afirmação étnica explícita, outros de renovação estética ou ainda de gênero.

$E$ se algumas dessas iniciativas utilizam equipamentos públicos - como o Samba da Vela, na Casa de Cultura de Santo Amaro - , a maioria, a exemplo da Cooperifa, funciona em espaços pouco afeitos a práticas consideradas culturais, como botecos, lajes, becos e esquinas. O termo "sarau" não deixa de constituir uma referência irônica às sofisticadas reuniões da elite em ambientes refinados e exclusivos.

Os casos aqui apresentados são mais voltados para a área de lazer, pois foi principalmente a partir do estudo desse tema, no Núcleo de Antropologia Urbana da USP, que surgiram tais categorias. Contudo, elas podem ser aplicadas a outros setores e atividades desde que, segundo a metodologia proposta, sigam os atores sociais "de perto e de dentro" na busca de regularidades em seus trajetos pela cidade.

\footnotetext{
PARA SABER MAIS:

- Da periferia ao centro: trajetórias de pesquisa em Antropologia Urbana. José Guilherme Cantor Magnani. 2012.

- A condição urbana: a cidade na era da globalização. Olivier Mongin. 2009.

- As cidades na economia mundial. Saskia Sassen. 1998.

- Cidades-regiões globais. Allen Scott, John Agnew, Edward Soja e Michael Storper. 2001.
}

JOSÉ GUILHERME CANTOR MAGNANI > Professor titular do Departamento de Antropologia da Universidade de São Paulo e Coordenador do Núcleo de Antropologia Urbana (NAU/USP) >

jmagnani@usp.br 